\title{
EVALUATION OF THE USAGE OF GEOTHERMAL ENERGY IN THE HOT WATER BOILER ROOM STRED I.
}

\author{
Ing. Soňa Gažíková ${ }^{1 *}$ \\ ${ }^{1}$ Slovak University of Technology in Bratislava, Faculty of Civil Engineering, Radlinského 11, 81005 Bratislava, Slovakia \\ *korespondenčni autor: sonka.gazikova@gmail.com
}

PŮVODNÍ VĚDECKÝ PŘíSPĚVEK

ORIGINAL SCIENTIFIC ARTICLE

\section{ABSTRACT}

The dominant source of energy in the hot water boiler house Stred I. in Velky Meder is geothermal energy, which is drawn from the VM -1 well, which was drilled in its courtyard in 2015. Based on documents and personal inspections of this boiler room, I created a geothermal circuit scheme of this hot water boiler room, where the experimental measurements took place. Part of this paper is a diagram of the geothermal circuit, a comparison of measured values within a selected characteristic day for summer and winter operation in 2020. Finally, the operation of the usage of geothermal energy in the hot water boiler room Stred I. is evaluated on all these indicators.

Key words: Geothermal energy, evaluation of operation, geothermal water, heat exchanger

\section{INTRODUCTION}

In October 2015, a geothermal well VM-1 was drilled in the courtyard of the hot water boiler room Stred I. in Velky Meder with a depth of $2450 \mathrm{~m}$, with borehole head temperature $\Theta_{0}=93{ }^{\circ} \mathrm{C}$ and with a flow rate $\mathrm{m}_{0}=10 \mathrm{l} / \mathrm{s}$. In 2015, there was also a complete reconstruction of the hot water boiler room. A few months later, in May 2016, a deep submersible pump with speed control was built into the geothermal well due to better regulation and usability of the geothermal well VM - 1. Thanks to this improvement, a higher usable average temperature was achieved - increased up to $\Theta_{0}=98^{\circ} \mathrm{C}$ and also the maximum possible flow rate of the well was increased to $\mathrm{m}_{0}=16 \mathrm{l} / \mathrm{s}$. The maximum possible usable energy potential of this well is $4890,4 \mathrm{~kW}$ at the considered cooling temperature of geothermal water to $25^{\circ} \mathrm{C}$.

\section{DIAGRAM OF GEOTHERMAL CIRCUIT}

This scheme is only a partial scheme of the whole scheme of the hot water boiler room, but it is dominant feature in this paper, therefore I will continue to deal only with this part from the whole scheme of the hot water boiler room Stred I. in Velky Meder.

The basic part of this scheme is the primary heat source - a geothermal well named VM-1 together with a deep submersile pump, which is built into this well. The specification of this well and pump is mentioned in the introduction chapter. The geothermal water (GTW) is then transported by preinsulated steel pipes to a degassing horizontal tank with a volume of $10 \mathrm{~m}^{3}$, where it is degassed of impurities, which are then discharged from the separator above the boiler room roof.

Subsequently, the geothermal water is transported to the heat exchangers. There are a total of 3 plate heat exchangers in this circuit. The first two are marked HEX1 and HEX2 and they are used for heat 
exchange between the primary heat transfer medium - geothermal water (GTW) and the secondary heat transfer medium - heating water and are of the type designation G-MAR NT100X PL120B-10 with a total heat output of $3098 \mathrm{~kW}(2 \times 1549 \mathrm{~kW})$. Subsequently, the cooled GTW is transported to a plate heat exchanger used for preheating hot water marked HEX, which is type G-MAR NT80M HU PL63CDL-16 with an output of $600 \mathrm{~kW}$. Figure 1 shows a diagram of this geothermal circuit together with the measuring points.

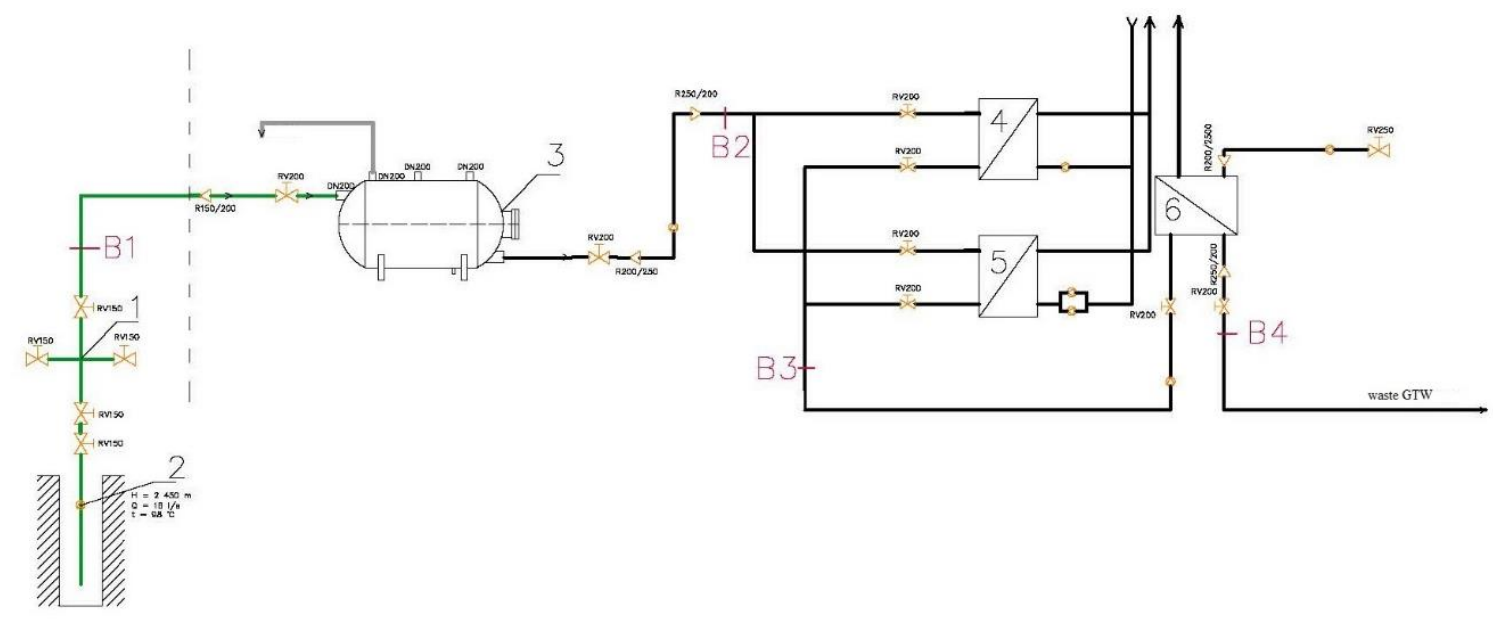

Fig. 1 Diagram of geothermal circuit in Velky Meder

The devices are marked in black color on the diagram (Fig. 1) as follows:

1 - geothermal well VM-1, 2 - deep submersible pump BORETS with speed control, 3 - degasing tank, 4 - plate heat exchanger HEX1, 5 - plate heat exchanger HEX2, 6- plate heat exchanger which is used for pre-heat of hot water named HEX.

Measuring points are marked in red color on the diagram (Fig. 1). The following quantities were measured at these points:

- B1 - borehole head temperature and flow rate of GTW,

- B2 - temperature od degassed GTW, which is then the heat transfer medium on the primary side of the plate heat exchangers HEX1 and HEX2,

- B3 - temperature of GTW at the outlet of the primary side of the plate heat exchangers, while it is also the temperature of GTW that enters into the heat exchanger named HEX, which is used to preheat the hot water,

- B4 - temperature of geothermal water leaving the hot water boiler room Stred I.

\section{EVALUATION OF THE USAGE OF GTW IN THE BOILER ROOM STRED I.}

Based on experimental measurements in the hot water boiler room Stred I., I selected one characteristic bday within the summer and winter operation in 2020 to evaluate the usage of geothermal energy in this system. For each of these characteristic days, a graph of measured values, a table and a graph showing the usable and waste amount of energy are shown.

\subsection{Evaluation of the usage of GTW in winter operation}

On January 10, 2020 as a characteristic day within the winter operation in the geothermal energy system (GES) in Velky Meder. The following Fig. 2 showing the measured values in 5-minute intervals. 


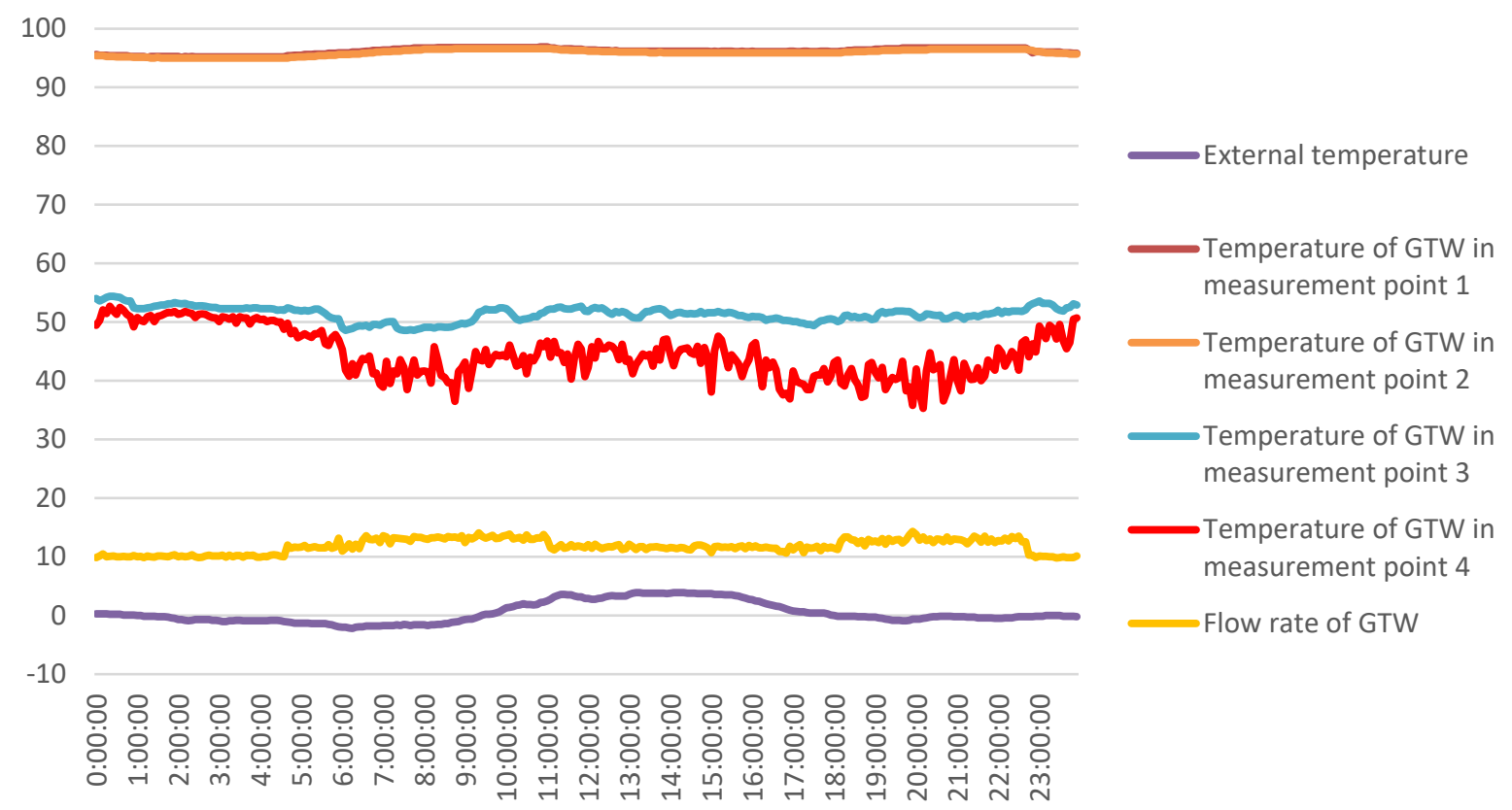

Fig. 2 The course of measured characteristic values in GES on January 10, 2020

On Figure 2 we can see the course of measured temperatures at individual measuring points according to Figure 1 and the flow of geothermal water pumped from well VM-1.

Average daily external temperature on January 10, 2020 was $0,44{ }^{\circ} \mathrm{C}$, average borehole head temperature on January 10,2020 was $96,15^{\circ} \mathrm{C}$, the average temperature at the inlet of the primary side to the circuit of plate heat exchangers HEX1 and HEX 2 was $95,92{ }^{\circ} \mathrm{C}$, the average temperature at the outlet of the circuit of these plate heat exchangers, which is also the inlet temperature to the heat exchanger HEX, which is used for preheating hot water was $51,43{ }^{\circ} \mathrm{C}$, the average daily temperature GTW leaving the boiler room Stred I. 10. 1. 2020 was $44,67{ }^{\circ} \mathrm{C}$ and the average flow of geothermal water was $11,791 / \mathrm{s}$.

From the graph in Figure 2 we can see that the borehole head temperature and the temperature of geothermal water at measuring point 2 (ie. after degassing) is almost the same, so it follows that heat losses in the distribution systems are minimal. The temperature of the geothermal water leaving circuit of the plate heat exchangers HEX1 and HEX2 (measuring point 3) is almost constant, ie. the abstraction of the GTW is almost uniform in winter operation.

The red line shows the temperature of the geothermal water leaving the hot water boiler room Stred I. We can see that the temperature of this water is about $50{ }^{\circ} \mathrm{C}$ until 5.00 , but after this time its temperature begins decrease, because there are almost no requirements for hot water (HW) until 5.00 am as most people are asleep at this time.

Based on the measured values from January 10, 2020, we created table for the usable amount, the usable amount and the waste amount of geothermal energy (GE) calculated in accordance with the following formulas:

The total usable amount of geothermal energy is calculated according to this following formula:

$$
E_{t}=\rho c_{s} M\left(t_{1}-t_{o}\right) / 3600 \quad[\mathrm{MWh}]
$$

Useful used amount of geothermal energy is calculated according to this following formula: http://doi.org/10.51704/cjce.2021.vol7.iss01.pp27-34 


$$
E_{u}=\rho c_{s} M\left(t_{1}-t_{4}\right) / 3600 \quad[\mathrm{MWh}]
$$

Waste amount of geothermal energy is calculated according to this following formula:

$$
E_{o}=\rho c_{S} M\left(t_{4}-t_{o}\right) / 3600 \quad[\mathrm{MWh}]
$$

Usable amount of GTW is calculated according to this following formula:

$$
M=24 n m_{s} 3,6 \quad[\mathrm{MWh}]
$$

Where:

$\rho-$ specific density

$\mathrm{c}_{\mathrm{s}}$ - specific heat capacity of geothermal water

$\left[\mathrm{kg} / \mathrm{m}^{3}\right]$

$\mathrm{M}$ - usable amount of GTW

$[\mathrm{kJ} /(\mathrm{kg} \cdot \mathrm{K}]$

$\mathrm{t}_{1}$ - borehole head temperature

$t_{0}$ - temperature of energetic used GTW

$\left[\mathrm{m}^{3}\right]$

$\left[{ }^{\circ} \mathrm{C}\right]$

$\mathrm{t}_{4}$ - temperature of waste GTW

$\mathrm{n}$ - number of days of operation

\begin{tabular}{|c|c|c|c|c|c|c|c|c|c|c|c|c|}
\hline $\mathrm{m}_{\mathrm{s}}$ & $\mathrm{M}$ & $t_{1}$ & $t_{2}$ & $t_{3}$ & $\mathrm{t}_{4}$ & $\mathrm{t}_{0}$ & $E_{t}$ & $E_{1}$ & $E_{2}$ & $E_{3}$ & $\mathrm{E}_{4}$ & \\
\hline$(1 / \mathrm{s})$ & $\left(\mathrm{m}^{3}\right)$ & $\left({ }^{\circ} \mathrm{C}\right)$ & $\left({ }^{\circ} \mathrm{C}\right)$ & $\left({ }^{\circ} \mathrm{C}\right)$ & $\left({ }^{\circ} \mathrm{C}\right)$ & $\left({ }^{\circ} \mathrm{C}\right)$ & (MWh) & (MWh) & (MWh) & (MWh) & (MWh) & \\
\hline 11,79 & 1018,69 & 96,15 & 95,92 & 51,43 & 44,67 & 25 & 82,41601 & 0,26504 & 51,54068 & 7,82421 & 22,78608 & MWh \\
\hline & & & & & & & 82416,01 & 265,04 & 51540,68 & 7824,21 & 22786,08 & $\mathrm{kWh}$ \\
\hline & & & & & & & 100 & 0,32 & 62,54 & 9,50 & 27,64 & $\%$ \\
\hline & & & & & & & & & \multicolumn{2}{|c|}{72,04} & & \\
\hline
\end{tabular}

$\mathrm{m}_{\mathrm{s}}-$ flow rate of GTW

Tab. 1 Usable, utilized and waste amount of energy on January 10, 2020

A graphical representation of Table 1 for better imagination is shown in Figure 3.

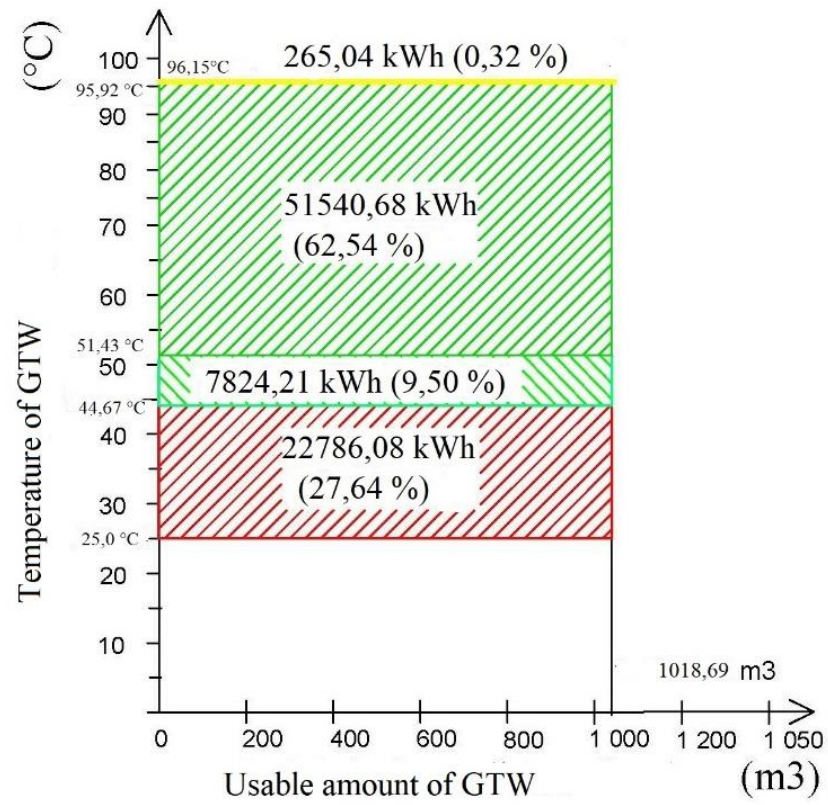

Fig. 3 Graphical representation of usable, used and waste amount of GE on January 10, 2020. 
Based on Figure 3, we can constate that the losses in the distribution system in GES in Velky Meder on January 10, 2020 was $265,04 \mathrm{kWh}$ GE $(0,32 \%)$ on the circuit heat exchangers HEX1 and HEX2. This plate heat exchangers are used to exchange heat between geothermal and heating water for heat supply. On January 10, 2020 these heat exchangers used 51540,68 $\mathrm{kWh} \mathrm{GE}(62,54 \%)$ and for preheating hot water on January 10, 2020 was consumed $7824,21 \mathrm{kWh}$ of the GE $(9,50 \%)$, and thus the total percentage share of useful used geothermal energy on 10 January 2020 was $72,04 \%$. The amount of geothermal energy waste on 10 January 2020 was 22786,08 kWh GE (27,64 \%).

The thermally used GTW is still used in the spa Thermal Corvinus and only then is discharged into the water recipient - the Izop canal. However, the subject of this article is not to describe the context of what happens with the GTW after leaving the hot water boiler room Stred I.

Based on measurements within the winter months, which are represented by the selected characteristic day, namely January 10, 2020, we can say that the operation of GES in Velky Meder in the hot water boiler room Stred I. is optimal in this period, because the thermal load of GES in winter months should be approximately $75 \%$ and in this case is $72,04 \%$ of the GE.

\subsection{Evaluation of the usage of GTW in summer operation}

July 7,2020 as a characteristic day within the summer operation in the geothermal energy system (GES) in Vel'ký Meder was selected. The following figure (Fig. 4) contains a graph showing the measured values in 5-minute intervals.

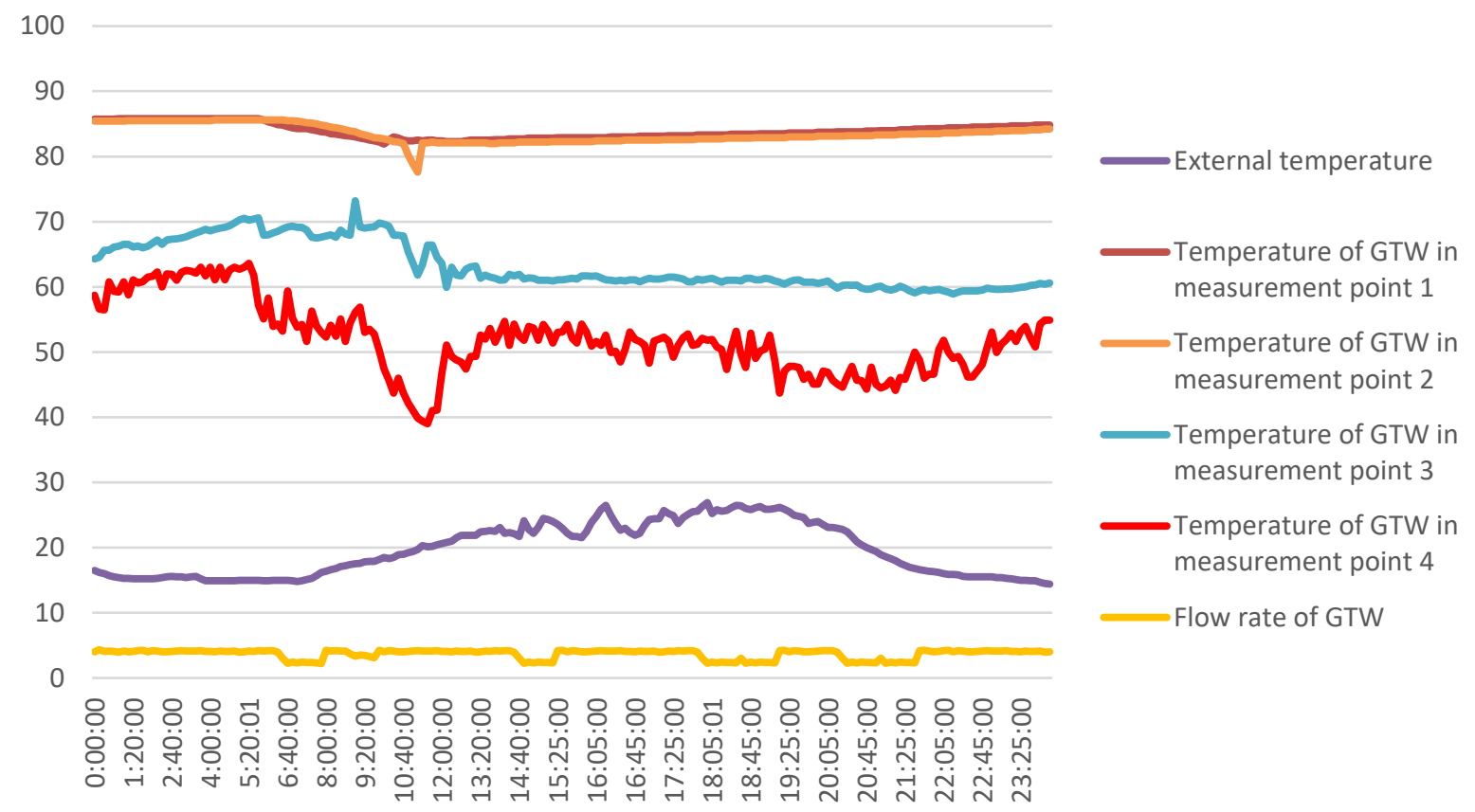

Fig. 4 The course of measured values in GES on July 7, 2020

In Figure 4 we can see the course of measured temperatures in individual measuring points according to Figure 1 and the flow of geothermal water pumped from well VM-1 on a selected characteristic day of summer operation.

Average daily external temperature July 7,2020 was $24,35^{\circ} \mathrm{C}$, average borehole head temperature on July 7, 2020 was $83,88{ }^{\circ} \mathrm{C}$, the average temperature at the inlet of the primary side to the circuit of plate heat exchangers HEX1 and HEX2 was $83,48{ }^{\circ} \mathrm{C}$, the average temperature at the outlet of the circuit of these plate heat exchangers, which is also the inlet temperature to the heat exchanger HEX, http://doi.org/10.51704/cjce.2021.vol7.iss01.pp27-34 
which is used for preheating hot water was $63,27{ }^{\circ} \mathrm{C}$, the average daily temperature GTW leaving the boiler room Stred I. on July 7, 2020 was $51,95{ }^{\circ} \mathrm{C}$ and the average flow of geothermal water was $3,681 / \mathrm{s}$.

Similar to the winter operation, in the summer operation from the graph in Figure 4 we can see that the borehole head temperature from the geothermal drill VM-1 and the temperature of geothermal water at measuring point 2 (i.e. after degassing) is almost the same, and therefore we can say that heat losses in pipes are minimal.

The temperature of the geothermal water leaving the system (red) is approximately $60.00^{\circ} \mathrm{C}$ up to 5.00 , as until this time there is no requirement for HW consumption. Following this hour, the temperature of the outgoing geothermal water from the GES in Velky Meder begins to decrease, as there is a higher demand for heated water.

In 2020, the course of measured values during summer operation was relatively even until the time period between 8.20 - 13.30 where there was a decrease in temperatures transported by GTW into the heat exchanger circuit HEX1 and HEX2 and also to the heat exchanger HEX, which is used for preheating hot water.

Based on these values, I calculated the usable, utilized and waste amount of GE and show it in the following table 2 .

\begin{tabular}{|c|c|c|c|c|c|c|c|c|c|c|c|c|}
\hline $\mathrm{m}_{\mathrm{s}}$ & $\mathrm{M}$ & $\mathrm{t}_{1}$ & $\mathrm{t}_{2}$ & $\mathrm{t}_{3}$ & $\mathrm{t}_{4}$ & $\mathrm{t}_{0}$ & $\mathrm{E}_{\mathrm{t}}$ & $\mathrm{E}_{1}$ & $\mathrm{E}_{2}$ & $\mathrm{E}_{3}$ & $\mathrm{E}_{4}$ & \\
\hline$(1 / \mathrm{s})$ & $\left(\mathrm{m}^{3}\right)$ & $\left({ }^{\circ} \mathrm{C}\right)$ & $\left({ }^{\circ} \mathrm{C}\right)$ & $\left({ }^{\circ} \mathrm{C}\right)$ & $\left({ }^{\circ} \mathrm{C}\right)$ & $\left({ }^{\circ} \mathrm{C}\right)$ & $(\mathrm{MWh})$ & $(\mathrm{MWh})$ & $(\mathrm{MWh})$ & $(\mathrm{MWh})$ & $(\mathrm{MWh})$ & \\
\hline 3,68 & 317,917 & 83,88 & 83,48 & 63,27 & 51,98 & 25 & 21,27834 & 0,14383 & 7,30544 & 4,07977 & 9,74931 & $\mathrm{MWh}$ \\
\hline
\end{tabular}

Tab. 2 Usable, utilized and waste amount of energy on July 7, 2020

A graphical representation of Table 2 for better imagination is shown in Figure 5.

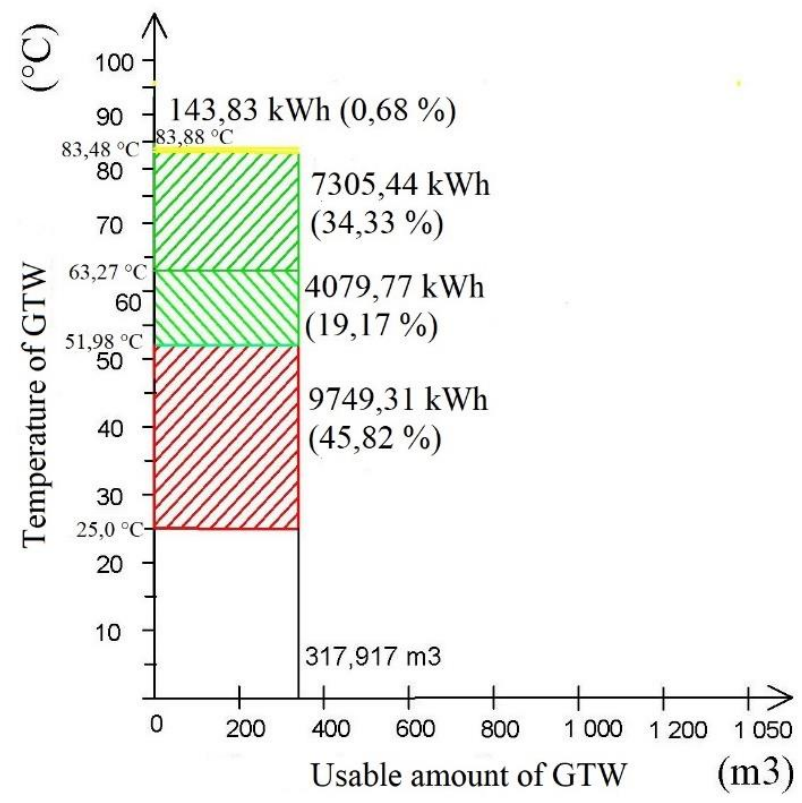

Fig. 5 Graphical representation of usable, used and waste amount of GE on July 7, 2020 
Based on Figure 5, we can tell that the losses in the distribution system in GES in Vel'ký Meder on July 7, 2020 was $143,83 \mathrm{kWh} \mathrm{GE}(0,68 \%)$ on the circuit heat exchangers HEX1 and HEX2. This plate heat exchangers are used to exchange heat between geothermal and heating water for heat supply. On July 7, 2020 these heat exchangers used 7305,44 kWh of GE (34,33\%) and for preheating hot water on July 7, 2020 was consumed $4079,77 \mathrm{kWh}$ of the GE $(19,17 \%)$, and thus the total percentage share of useful used geothermal energy on July 7, 2020 was $53,5 \%$. The amount of waste geothermal energy on July 7, 2020 was 9749,31 kWh GE $(45,82 \%)$.

In summer operation, the percentage of the waste amount of geothermal energy and used geothermal energy is the unfavorable in contrast to winter operation, and therefore operation must be optimized for the summer period. It is advisable to optimize this operation by reducing the flow rate of GTW entering the system during summer operation, which could be achieved by switching on the depth pump with frequency converter also in the summer months, as it is switched off in July and August

\section{CONCLUSION}

During the characteristic day of winter operation, the usable amount of GE was 72,04\% and the waste amount of GE was $27,64 \%$. In summer operation, these values were $53,50 \%$ for the useful amount of GE and 45,82 \% for waste amount of the GE. In winter operation, more GE is used because the GTW is used for both functions - heating and preheating the hot water, in contrast to summer operation, where GE is used only for preheating the hot water. Another big difference in these operations is that during the summer months (especially July and August) the submersible deep pump with frequency converter is switched off, but on other hand in winter operation this pump is switched on.

Based on measurements within the winter months, which are represented by the selected characteristic day, namely January 10, 2020, we can say that the operation of GES in Velky Meder in the hot water boiler room Stred I. is optimal in this period, because the thermal load of GES in winter months should be approximately $75 \%$ and in this case is $72,04 \%$ of the GE.

In summer operation, the percentage of the waste amount of geothermal energy and used geothermal energy is the unfavorable in contrast to winter operation, and therefore operation must be optimized for the summer period. It is advisable to optimize this operation by reducing the flow rate of GTW entering the system during summer operation, which could be achieved by switching on the depth pump with frequency converter also in the summer months, as it is switched off in July and August.

\section{Acknowledgment}

This work was supported by the Ministry of Education, Science, Research and Sport of the Slovak Republic under VEGA Grant 1/0304/21.

\section{References}

[1] HALÁS O.: Using of the geothermal energy for heating in Vel'ky Meder. In: Renewable energy sources 2017 [electronic source]: Proceedings of the 17th Scientific and Professional Conference with Foreign Participation on "Nearly Zero Energy Buildings".Štrbské Pleso, SR, 9. - 10 5. 2017. 1. vyd. Bratislava: SSTP, 2017, CD-ROM, s. 73-76. ISBN 978-80-89878-10-9.

[2] PETRAŠ, D. a kol.: Renewable energy sources for the low-entalphy systems. JAGA, Bratislava 2009, 223 str., ISBN 978-80-8076-075-5

[3] TAKÁCS, J. - GAŽÍKOVÁ, S.: Good example of a geothermal energy system solution for the heat supply of Vel'ký Meder. In Heating 2019 [electronic source] : Proceedings of the 27th International Scientific and Professional Conference on Smart Technologies and Innovation in Heat Supply.Podbanské, Vysoké Tatry, 1. - 5. april 2019. 1. vyd. Bratislava: SSTP, 2019, CDROM, s. 193-198. ISBN 978-80-89878-42-0. 
[4] TAKÁCS J. - GAŽÍIKOVÁ, S.: Using geothermal energy for centralized heat supply in Vel'ký Meder. In: JÁNOŠKOVÁ, T. Heat measurement and budgeting of heat 2019. Bratislava: SSTP, 2019. ISBN 978-80-89878-52-9.

[5] Data processed separately on the basis of documentation from the control PC for the system in Vel'ký Meder, which works in Niagara control software

[6] Data from the operation of the central boiler house in Vel'ký Meder MPBH spol. s r.o. 